Journal of Computer Science 8 (9): 1520-1530, 2012

ISSN 1549-3636

(C) 2012 Science Publications

\title{
A Study on Nuclear Blast Overpressure on Buildings and other infrastructures using Geospatial Technology
}

\author{
${ }^{1}$ Vijayaraghavan, C., ${ }^{1}$ D. Thirumalaivasan and ${ }^{2}$ R. Venkatesan \\ ${ }^{1}$ Institute of Remote Sensing, Anna University, Chennai, India \\ ${ }^{2}$ Radiological Safety Division, \\ Indira Gandhi Centre for Atomic Research, Kalpakkam, India
}

\begin{abstract}
An Improvised Nuclear Device or nuclear bomb of yield 10 kiloton to 20 kiloton explodes in any major city due to terrorism or any other reason can cause catastrophic damages on the building's and other infrastructures and also shutting down of critical life-safety systems.. The explosion may produce blast overpressure, thermal radiation and harmful instant and delayed nuclear radiations. The buildings and other Civil Engineering structures may be highly vulnerabke due to the blast overpressure from the explosion and thermal radiation. In this present study Remote Sensing and Geographical Information System is effectively utilized to model the blast affected zone from the ground Zero of the study area. This study also introduces different emperical methods to estimate blast loads and structural response. The purpose is to describe the blast effects of a nuclear explosion, thereby informing people of the real dangers posed by nuclear weapons. Therefore, as a case study, we consider a hypothetical City as a target for detonation. Due to security reasons the data for existing City is not used for this study purpose. The study area is hypothetically detonated with a 15 kiloton yield nuclear explosion as surface blast and wind spped is assumed as 5 meters per second.
\end{abstract}

Key words: blast overpressure, yield, internal structural, densely populated, nuclear explosion, geographical information system, hiroshima during, kiloton explosion

\section{INTRODUCTION}

The detonation of a Nuclear Bomb or a nuclear device exploded in any city either by accident, terrorism, or any other reason, it is likely to wipe out hundreds of thousands of people which may cause a Local Disaster. This disasterous effect will mark the end of civilization in the countries concerned and will cause radioactive contamination of whole continents and might terribly damage to the environment and ecology (Richard and Garwin, 2010). A nuclear weapon when detonated produces $50 \%$ of Blast energy and $35 \%$ of Thermal energy. The release of $15 \%$ of the remaining energy is observed as various type of nuclear radiations which constitutes of $5 \%$ of initial nuclear radiation produced within a minute of the explosion. These are mostly gamma rays and neutrons. The last $10 \%$ of the energy is emitted over a period of time represents the residual (or delayed) nuclear radiation (Glasstone and Dolan, 1977). An explosive blast from a large weapon drives air away from the site of the explosion. This produces sudden change in air pressure. This static overpressure can crush objects and high winds called dynamic pressure can move the objects suddenly or knock them down (Mendis and Ngo, 2002). Large buildings are destroyed by the overpressure, whereas people and objects are destroyed by the wind. For example, consider the effects of a 1-Megaton (Mt) air burst on things 4 miles [6 km] away. During the time of explosion, due to the blast overpressure of around 5 psi, the impact on the wall of typical two- story house will be more than 180 tons. Apart from this over pressure, there would be a wind of $160 \mathrm{mph}[255 \mathrm{~km}]$ which may be more than sufficient to create fatal collisions on the existing population and nearby objects. The magnitude is generally measured in pounds per square inches. The blast overpressure will decreases as the distance increase from the point of detonation or Ground Zero (Remennikov, 2003).

Yield capacity of nuclear weapons: 'Yield' is the measure of the energy released when a nuclear weapon explodes, which is measured in kilotons or megatons of TNT (Tri Nitro Toluene) equivalent, i.e., as much energy as thousands or millions of tons of chemical high explosive (Phillips, 2003).

Corresponding Author: Vijayaraghavan, C., Institute of Remote Sensing, College of Engineering, Anna University, Chennai, India 


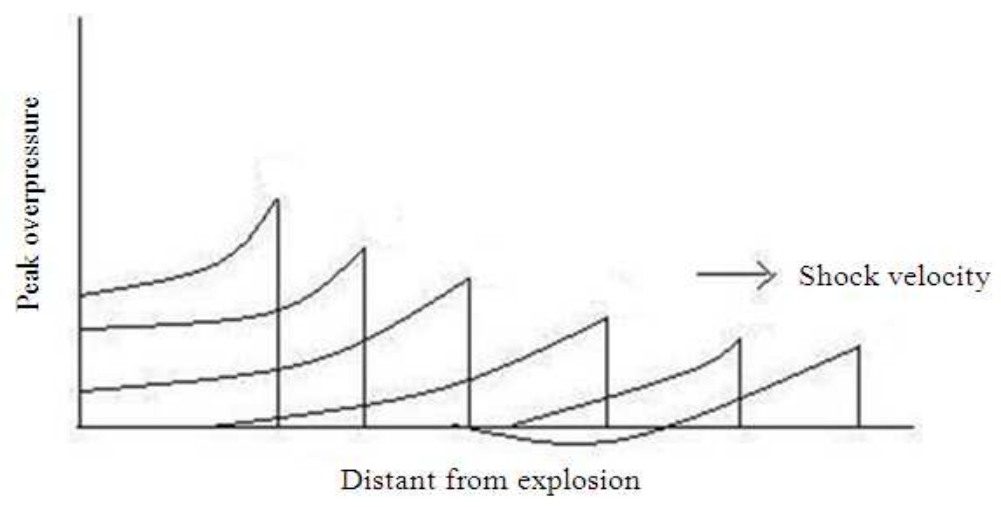

Fig. 1: Blast wave propagation Source: Mays and Smith (1995)

This quantification is done in terms of the amount of conventional explosive it would take to create the same blast effect. The amount of explosives used during the 1995 bombing of the Federal Building in Oklahoma City, USA, has been estimated to be around 2.2 tons of TNT. One ton of TNT releases 4.2 billion joules of energy upon detonation. This explosion in Oklahoma City caused extensive damage to the building and killed 168 people and more than 500 injured (Mays and Smith, 1995). The weapons used in Hiroshima and Nagasaki was developed by the Manhattan Project during World War II that had yields of 15 and 22 kilotons respectively, nearly ten thousand times the amount of explosive used in Oklahoma City. It derived its explosive power from the nuclear fission of uranium 235. In this blast, approximately 600 milligrams of mass were converted into energy and exploded with a high energy equivalent to 15 kilotons (15000 tons) of TNT. It killed approximately 140,000 people. Thermonuclear weapons, currently possessed by several countries, could have yields of hundreds or thousands of kilotons (Hiroshima, 1981).

\section{Related works:}

Explosions and blast phenomenon: An explosion is defined as a large-scale, rapid and sudden release of energy energy in the form of light, heat, sound and a shock wave. Any explosion can be classified as either as physical, nuclear or chemical events based on their nature. In case of physical explosions, energy may be released from the catastrophic failure of a cylinder of compressed gas, volcanic eruptions or even mixing of two liquids at different temperatures. In a nuclear type of explosions, energy is released from the formation of different atomic nuclei by the redistribution of the protons and neutrons within the interacting nuclei. In the case of a chemical explosion, the rapid oxidation of fuel elements (carbon and hydrogen atoms) is the main source of energy in the case of chemical explosions (Mays and Smith, 1995). As explosions can be classified into three categories based on their nature, the explosive materials can be classified into three categories according to their physical state as solids, liquids or gases. Solid explosives are the best known form of hihg explosives for its blast effects. Based on the sensitivity to ignition, these solid explosives can be further classified as primary or secondary explosives. The former one is that can be easily detonated by simple ignition from a spark, flame or impact. Materials such as mercury fulminate and lead azide fall under this primary explosives category. The latter one, that is, the Secondary explosives when detonated create blast (shock) waves which can result in widespread damage to the surroundings. Trinitrotoluene (TNT) and ANFO are the examples of secondary category of explosives. The detonation of a condensed high explosive generates hot gases which expands forcing out the volume it occupies. These hot gases have a pressure up to 300 kilo bar and a temperature of about $3000^{\circ} \mathrm{C}-4000^{\circ} \mathrm{C}$. As a resultant of this hot gas expansion, a layer of compressed air (known as blast wave) forms in front of this gas volume containing most of the energy released during the explosion (Bangash, 1993).

The pressure of these blast wave increases instantaneously to a high value that is above the ambient atmospheric pressure. This pressure created in the blast waves is called as the side-on overpressure. This pressure thus created decays as the shock wave expands outward from the source of explosion. After a short time, the pressure behind the front may drop below the ambient pressure (Fig. 1). This is referred to as a negative phase, during which a partial vacuum is created and air is sucked in. This phenomenon is also accompanied by high suction winds which carry the debris for long distances away from the source of explosion (Mendis and Ngo, 2002).

Mays and Smith (1995) and TM5-1300 (1990) gives the full discussion and detailed charts for predicting these blast pressures and blast durations. Some representative numerical values of peak reflected overpressure are given in table below (Table 1). 
Table 1: Peak reflected overpressures Pr (in MPa) with different W-R combinations - Source: Mays and Smith (1995)

\begin{tabular}{|c|c|c|c|c|}
\hline W & $100 \mathrm{~kg}$ & $500 \mathrm{~kg}$ & $1000 \mathrm{~kg}$ & $2000 \mathrm{~kg}$ \\
\hline $\mathrm{R}$ & TNT & TNT & TNT & TNT \\
\hline $1 \mathrm{~m}$ & 165.8 & 354.5 & 464.5 & 602.9 \\
\hline $2.5 \mathrm{~m}$ & 34.20 & 89.40 & 130.8 & 188.4 \\
\hline $5 \mathrm{~m}$ & 6.650 & 24.80 & 39.50 & 60.19 \\
\hline $10 \mathrm{~m}$ & 0.850 & 4.250 & 8.150 & 14.70 \\
\hline $15 \mathrm{~m}$ & 0.270 & 1.250 & 2.530 & 5.010 \\
\hline $20 \mathrm{~m}$ & 0.140 & 0.540 & 1.060 & 2.130 \\
\hline $25 \mathrm{~m}$ & 0.090 & 0.290 & 0.550 & 1.080 \\
\hline $30 \mathrm{~m}$ & 0.060 & 0.190 & 0.330 & 0.630 \\
\hline
\end{tabular}

Blast effects on buildings and residents: As defined earlier, an explosion is an extremely rapid release of energy and produces a shock wave. A shock wave thus produced consists of highly compressed air traveling at supersonic velocities and radiate outward from the explosion source. These shock wave tend to expand and the pressure decreases rapidly (with the cube of the distance). When these waves meet a surface that is in the line-of-sight of the explosion, it is reflected and amplified by a factor of up to thirteen. There is also an exponential decrease in pressure that decays rapidly over time. This has a very short span of existence, measured typically in thousandths of a second, or milliseconds. Diffraction effects are caused when these waves meet the corners of a building and may act to confine the air-blast thus prolonging its duration (TM 5-1300, 1990). After a duration of the explosive event, the shock wave become negative and thus creating a suction. Vaccum is created behind the shock wave, where air rushes in, creating a powerful wind or drag pressure on all the surfaces of the building. This wind carries the flying debris in the vicinity of the detonation. The magnitude of the pressure acting on a targeted building can be greater than these other hazards. The peak pressure meaures in excess of 100 pounds Per Square Inch (PSI) on a building in an urban setting for a vehicle weapon parked along the curb. This pressure level is sufficient to cause major damages and failures. The damages on the side of the building facing the explosion may be significantly more severe than on the opposite side, since the explosive pressures decay extremely rapidly with increase in the distance from the source. Thus, direct air-blast damages tend to cause more localized damages (FEMA, 2010).

Eventhough there is an anticipation to the extent and severity of damage and injuries in an explosive event, prediction with perfect certainty is practically not feasible. Despite these uncertainties, from the past events, it is possible to give some general indications of the overall level of damage and injuries to be expected. This general prediction can be done based on the size of the explosion, distance of the object from the event and assumptions about the nature and materials of construction of the building (Glasstone and Dolan, 1977).

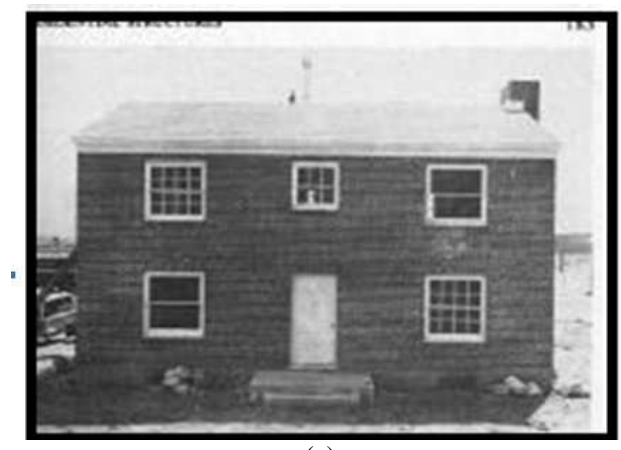

(a)

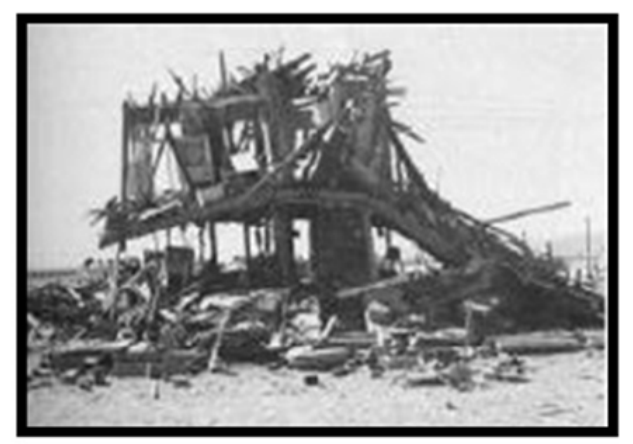

(b)

Fig. 2: Unreinforced brick house experiencing 5psi overpressure. (a) Before nuclear explosion at the nevada test site. (b) After nuclear explosion at the nevada test site. (Source: US federal emergency management agency)

Glass is often the weakest part of a building, which breaks even at a low pressure compared to other materials used for components such as the floors, walls, or columns. Hence from the past incidents, glass breakage may extend for miles in large external explosions. Even in this glass breakage, high-velocity glass fragments are shown to be a major contributor to injuries in such incidents. Falling glass poses a major hazard to passersby on the sidewalks below and calls for prolonged post-incident rescue and cleanup efforts of tons of glass debris on the street. The figure (Fig. 2a and b) shows the result of Nevada nuclear Test Site of United States, where the masonry building collapsed at a peak over pressure of 5 psi.

The structures may be classified as load bearing structures and framed structures (Reinforced Cement Concrete). Most probably the framed structures are engineered structures and these types of structures can withstand a pressure of 5-10 psi. As far as nuclear blast loading in Indian cities are concerned the buildings are categorized according to materials used, year of construction, design of structures. The buildings constructed during 1970s and 1980s were load bearing structures and the degree of damage may be high. 


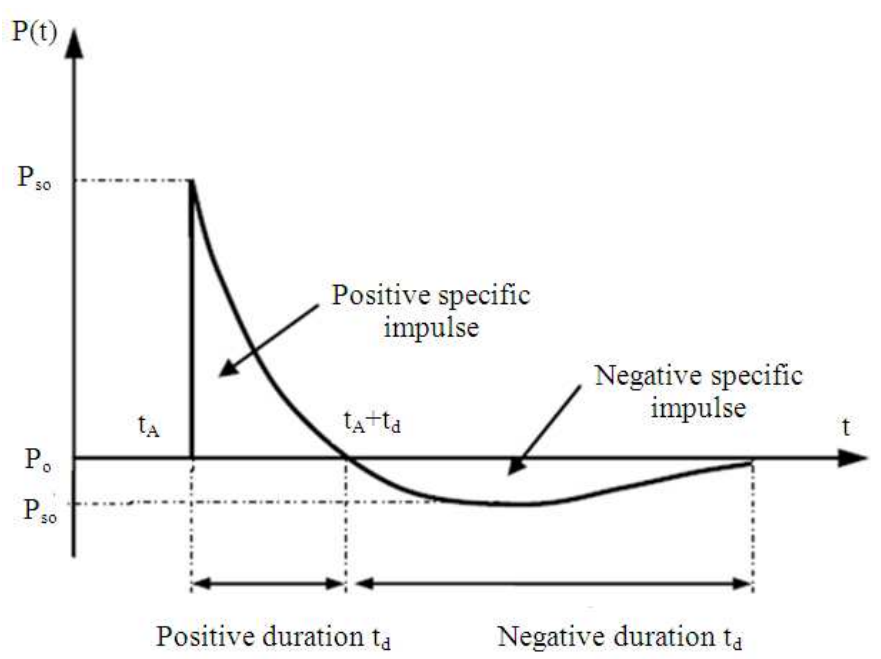

Fig. 3: Blast wave pressure-Source: Mays and Smith (1995)

Table 2: Impacts of peak overpressure of blast on Buildings and Human

\begin{tabular}{lll}
\hline Peak Overpressure $(\mathrm{psi})$ & Type of structure & Degree of damage \\
\hline $0.15-0.22$ & Typical window glass breakage & Moderate \\
$0.5-1.1$ & Minor damage to some buildings & Moderate \\
$1.1-1.8$ & Panels of sheet metal buckled & Moderate (broken) \\
$1.8-2.9$ & Failure of concrete block walls & Severe \\
Over 5.0 & Collapse of wood framed buildings & Severe \\
$4-7$ & Serious damage to steel framed buildings & Severe \\
$6-9$ & Severe damage to reinforced concrete structures & Moderate \\
$10-12$ & Probable total destruction of most buildings & Severe (collapse) \\
Peak Overpressure (psi) & Type of injury to people in the open & \\
5 & Threshold for eardrum rupture & \\
50 & Threshold for serious lung damage & \\
\hline
\end{tabular}

Source: Explosive shocks in air, Kinney and Graham, 1985; facility damage and personnel injury from explosive blast, Montgomery \& Ward, 1993; and the effects of nuclear weapons, $3^{\text {rd }}$ edition, Glasstone and Dolan (1977)

The table above (Table 2) shows the stability of the structures against blast pressure and types of injuries to the exposed population. From the table it is clear that the masonry and wooden buildings may collapse for blast pressure 5 psi or even less (Ramana, 1998). The blast wave can crush organs of human bodies. About 20 psi of overpressure can cause damage to lungs and rupture of eardrums. However, the major cause of death or injury to humans is the effects of the winds and missiles accompanying the shock wave. A wind pressure at $15-20$ psi can throw a person at several hundred $\mathrm{km} / \mathrm{hour}$. Glass breakage at an overpressure of 5 psi, could cause more than 400 pieces of glass per square foot of surface (each weighing about $5 \mathrm{~g}$ on the average), flying at speeds of $200 \mathrm{~km} /$ hour or more [Simon and Schuster].

Analysis of nuclear blast loading and blast overpressure: Nuclear explosives when detonated create blast waves which can cause extensive damage to the surroundings as in the case of trinitrotoluene (TNT).
The detonation of a high explosive or nuclear device will generates hot gases under pressure up to 300 kilo bar and a temperature more than $3000^{\circ} \mathrm{C}$. The hot gas expands forcing out the volume it occupies. As a consequence, a layer of compressed air (blast wave) forms in front of this gas volume containing most of the energy released by the explosion. Blast wave instantaneously reaches above the ambient atmospheric pressure. This is referred to as the side-on overpressure that decays as the shock wave expands outward from the explosion source. After a short time, the pressure behind the front may drop below the ambient pressure (Fig. 3). During such a negative phase, a partial vacuum is created and air is sucked in. Hence the outside atmospheric airs along with debris will forcibly inward towards the vacuum space (Ngo et al., 2007).

The amount of energy released in a detonation and the distance from the explosion are the primary factors upon which all the blast parameters depend. An universal normalized description of the blast effects can be given by, scaling distance relative to $(\mathrm{E} / \mathrm{Po})^{1 / 3}$ and scaling 
pressure relative to Po. Here, E is the energy released (kJ) and Po, the ambient pressure (typically $100 \mathrm{KN}$ $\mathrm{m}^{-2}$ ). However, it is a general practice to express the basic explosive input or charge weight $\mathrm{W}$ as an equivalent mass of TNT. Results are then given as a function of the dimensional distance parameter (scaled distance) $\mathrm{Z}=\mathrm{R} / \mathrm{W}^{1 / 3}$, where $\mathrm{R}$ is the actual effective distance from the explosion. $\mathrm{W}$ is generally expressed in kilograms. Scaling laws provide parametric correlations between a particular explosion and a standard charge of the same substance (Bangash, 1993).

Blast wave parameters for conventional high explosive materials have been the focus of a number of studies during the 1950's and 1960's. Estimations of peak overpressure due to spherical blast based on scaled distance $\mathrm{Z}=\mathrm{R} / \mathrm{W}^{1 / 3}$ was introduced by Brode (1955) as:

$\mathrm{P}_{\mathrm{So}}=6.7 / \mathrm{Z}^{3}+1$ bar $\quad\left(\mathrm{P}_{\mathrm{So}}>10 \mathrm{bar}\right)$

$$
\begin{gathered}
\text { PSo }=0.975 / \mathrm{Z}+1.455 / \mathrm{Z} 2+5.85 / \mathrm{Z} 3 \\
-0.019 \text { bar }(0.1 \text { bar }<\text { Pso }<10 \text { bar })
\end{gathered}
$$

The relationship to calculate the maximum blast overpressure, Pso, in bars, for a high explosive charge detonates at the ground surface was introduced by Newmark (1961). This is given as follows:

Pso $=6784(\mathrm{~W} / \mathrm{R} 3)+93\{\mathrm{~W} / \mathrm{R} 3\} 1 / 2$
' $\mathrm{W}$ ', is the yield of nuclear explosion in terms of tones and ' $R$ ', is the distance from ground zero in terms of meters. The blast Peak overpressure (Pso) calculated using the Newmark (1961) relationship are given in the table (Table 3).

Mills et al. (1987) introduced an expression of the peak overpressure in $\mathrm{KPa}$ in which $\mathrm{W}$ is expressed as the equivalent charge weight in kilograms of TNT and $\mathrm{Z}$ is the scaled distance. This is given below:

PSo $=1772 / Z 3-114 / Z 2+108 / Z$

To determine the peak overpressure due to the blast of nuclear explosion, the above four methods may be used (Eq. 1-4). Comparing all the four methods, predicton by Newmark and Hansen method is the simple and time consuming method. In this method yield is substituted in terms of tones and distance in terms of meters. This method is also adopted in the open source HOTSPOT (developed by NARAC, Lawrence Livermore National Laboratory, USA). The values obtained from the Newmark and Hansen method is also compared and cross checked with the source (HOTSPOT). The figure below (Fig. 4) shows the graph for peak over pressure and distance from ground zero for $15 \mathrm{KT}$ yield nuclear explosion. As the distance increases pressure decreases which show the decaying of pressure.

For damage assessment the pressure zones must be analyzed according to peak over pressure. Hence in the above Newmark and Hansen formula pressure is fixed as maximum 75 psi and minimum 0.5 psi (National Atmospheric Release Advisory Centre (NARAC).

\begin{tabular}{|c|c|c|c|c|}
\hline \multirow{2}{*}{$\begin{array}{l}\text { Yield }(\mathrm{W}) \\
\text { Tones }\end{array}$} & \multirow{2}{*}{$\begin{array}{l}\text { Distance from ground } \\
\text { zero }(\mathrm{R}) \text { in meters }\end{array}$} & \multicolumn{3}{|c|}{--1 } \\
\hline & & Bar & Psi & $\mathrm{KPa}$ \\
\hline & 1000 & 0.09980 & 1.44720 & 9.9784 \\
\hline & 2000 & 0.03370 & 0.48920 & 3.3730 \\
\hline \multirow[t]{3}{*}{1000} & 3000 & 0.01820 & 0.26400 & 1.8200 \\
\hline & 4000 & 0.01170 & 0.17010 & 1.1731 \\
\hline & 5000 & 0.00840 & 0.12180 & 0.8400 \\
\hline \multirow[t]{5}{*}{5000} & 1000 & 0.24190 & 3.50800 & 24.190 \\
\hline & 2000 & 0.07770 & 1.12780 & 7.7776 \\
\hline & 3000 & 0.04127 & 0.59840 & 4.1270 \\
\hline & 4000 & 0.02650 & 0.38450 & 2.6520 \\
\hline & 5000 & 0.01887 & 0.27360 & 1.8870 \\
\hline \multirow[t]{5}{*}{10000} & 1000 & 0.36190 & 5.24500 & 36.190 \\
\hline & 2000 & 0.11240 & 1.62980 & 11.240 \\
\hline & 3000 & 0.05910 & 0.85690 & 5.9100 \\
\hline & 4000 & 0.03780 & 0.54810 & 3.7800 \\
\hline & 5000 & 0.02680 & 0.38860 & 2.6800 \\
\hline \multirow[t]{5}{*}{15000} & 1000 & 0.46194 & 6.69830 & 46.194 \\
\hline & 2000 & 0.14006 & 2.03087 & 14.006 \\
\hline & 3000 & 0.07308 & 1.05966 & 7.3080 \\
\hline & 4000 & 0.04661 & 0.67584 & 4.6610 \\
\hline & 5000 & 0.03303 & 0.47893 & 3.3030 \\
\hline \multirow[t]{5}{*}{20000} & 1000 & 0.55610 & 7.99820 & 55.160 \\
\hline & 2000 & 0.31660 & 4.59070 & 31.660 \\
\hline & 3000 & 0,08510 & 1.23395 & 8.5100 \\
\hline & 4000 & 0.05410 & 0.78460 & 5.4110 \\
\hline & 5000 & 0.03828 & 0.55510 & 3.8280 \\
\hline
\end{tabular}

Table 3: Calculated Peak over Pressure (Pso) for $5 \mathrm{KT}, 10 \mathrm{KT}, 15 \mathrm{KT}$ and $20 \mathrm{KT}$ detonation using Newmark and Hansen formula 


\section{J. Computer Sci., 8 (9): 1520-1530, 2012}

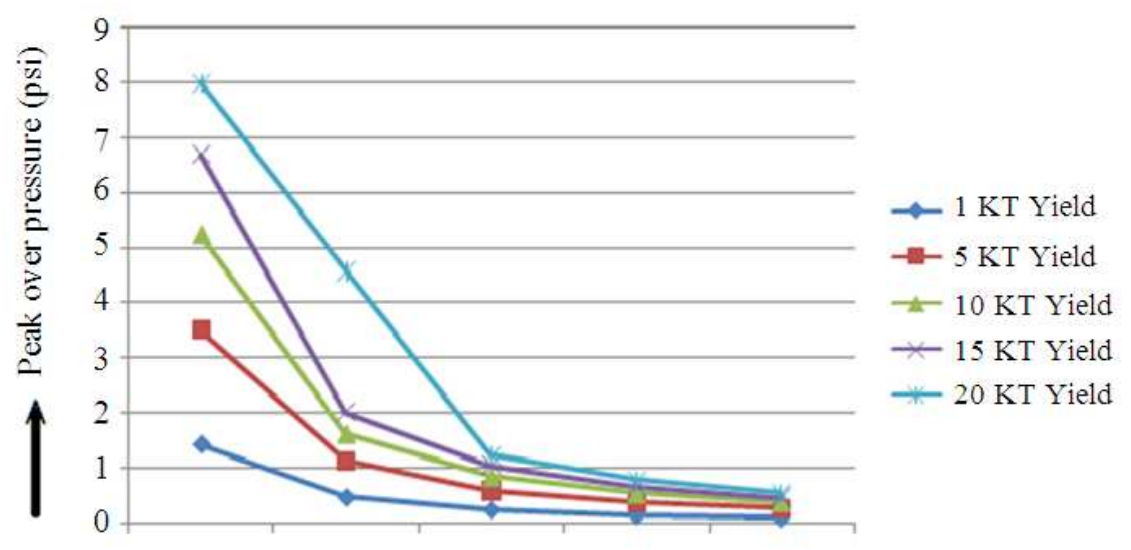

Distance from ground zero $(\mathrm{kms})$

Fig. 4: Graph-Blast wave pressure Vs Distance from ground zero for 15 KT nuclear explosion (Newmark and Hansen

Table 4: Distance from ground zero for various blast over pressure for $15 \mathrm{KT}$ detonation using Newmark and Hansen formula

\begin{tabular}{|c|c|c|c|c|c|c|}
\hline \multicolumn{2}{|c|}{ Overpressure } & \multicolumn{5}{|c|}{ Radius/ Distance in Kms from Ground Zero for various yields } \\
\hline psi & $\mathrm{KPa}$ & 1 Kilotons & 5 Kilotons & 10 Kilotons & 15 Kilotons & 20 Kilotons \\
\hline 75 & 517.11 & 0.13 & 0.21 & 0.27 & 0.32 & 0.33 \\
\hline 50 & 344.74 & 0.15 & 0.25 & 0.32 & 0.38 & 0.40 \\
\hline 30 & 206.84 & 0.19 & 0.32 & 0.40 & 0.47 & 0.50 \\
\hline 20 & 137.90 & 0.22 & 0.38 & 0.48 & 0.57 & 0.59 \\
\hline 15 & 103.42 & 0.26 & 0.44 & 0.54 & 0.66 & 0.68 \\
\hline 80 & 55.160 & 0.35 & 0.59 & 0.74 & 0.91 & 0.94 \\
\hline 50 & 34.470 & 0.45 & 0.76 & 0.96 & 1.18 & 1.21 \\
\hline 30 & 20.680 & 0.63 & 0.90 & 1.53 & 1.70 & 3.42 \\
\hline 0.5 & 3.4500 & 1.90 & 3.25 & 4.09 & 4.86 & 5.15 \\
\hline
\end{tabular}

The table given above (Table 4) shows the peak over pressure and corresponding distance from ground zero.

\section{MATERIALS AND METHODS}

Design of Study area: The study area is planned and designed as per second master plan for Chennai metropolitan area (2008) and Development Control Rules (DCR, 2004) of Chennai Metropolitan Development Authority. The Total area of the Model City is around 125 square kilometers. As per the Census of India 2011, the density of population of Chennai city is 22000 per square kilometer. Hence the model city is assumed and designed with a population of around 2.5 million (25 lakhs). The figure (Fig. 5) shows the raster image of the model city using ARC GIS software.

The infrastructures and the basic amenities are planned according to the second master plan of Chennai
Metropolitan Area. The land use details of the study area is compared with the Chennai Metropolitan land use area and also shown in table below (Table 5).

The buildings in the study area are assumed to be RCC structures with single storey to multi storied buildings. The study area also consists of Airport, Railway station, Coastal zone and beach, National highways. The roads are planned with a widening of 10 $\mathrm{m}$ to $30 \mathrm{~m}$. The raster data was later digitized using ARC GIS. The pie chart given in figure below (Fig. 6) gives the details of land use in the study area.

Modelling the blast effects and damage assessment using GIS: In the study area a hypothetical 15 Kilo ton nuclear detonation was created near the Residential Zone. The wind speed was assumed as $5 \mathrm{~m} \mathrm{sec}^{-1}$ and the direction of wind is $180^{\circ}$ (wind from South to North). The peak over pressure is modeled using GIS. The table (Table 6) shows the extent of the affected buffer zone. 


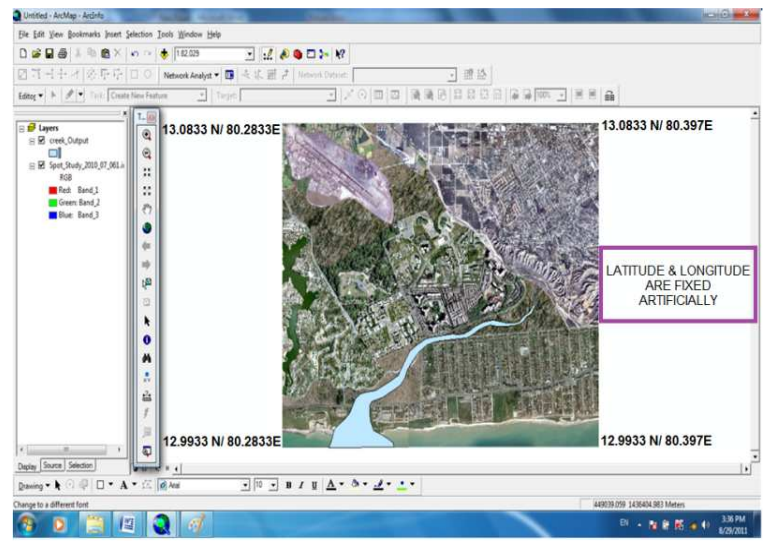

Fig. 5: Raster Image of the study area (Model City)

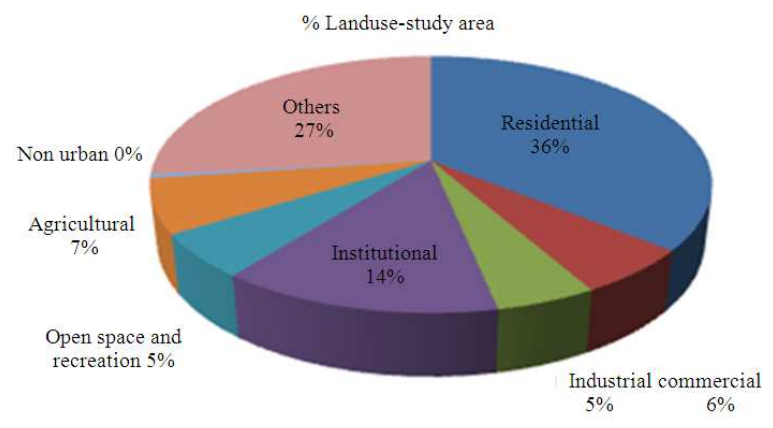

Fig. 6: Pie chart of the study area

Table 5: Area details and \% of land used for amenities and infrastructures in study area

\begin{tabular}{lll} 
& \multicolumn{2}{l}{ Study area } \\
Details of Infra structures & --------- & \\
\hline Residential & Extent in Sq. Km. & $\%$ \\
Commercial & 55.10 & 43.93 \\
Industrial & 80.00 & 6.390 \\
Institutional & 70.00 & 5.590 \\
Open space and recreation & 22.80 & 17.57 \\
Agricultural & 3.850 & 3.080 \\
Non urban & 1.200 & 0.960 \\
Others (Vacant, forest, hills, & 0.700 & 0.560 \\
low lying, water bodies) & 26.54 & 21.20 \\
\hline
\end{tabular}

Blast is measured by the overpressure and dynamic pressure that it produces. Initially, near the point of detonation for a ground blast (also referred to as ground zero), the overpressure is extremely high (thousands of pounds per square inch [psi] expanding out in all directions from the detonation at hundreds of miles per hour). With increasing distance from ground zero, the overpressure and speed of the blast wave dissipate to where they cease to be destructive. After initial dissipation, the blast wave slows to about the speed of sound. After the first mile it travels, the wave takes approximately five seconds to traverse the next mile. This is enough time for a person with the right information to seek basic shelter for safety. The blast affected zones or rings shown in figure above (Fig. 7) indicates the distance from ground zero and corresponding peak over pressure in terms of pounds per square inches (Psi).

Due to this explosion, an area of around 17 square kilometers was affected by the blast peak over pressure. During the time of nuclear explosion, the infrastructures and people living in nearby areas may also affect by thermal radiations. This may lead to secondary fire accident. As per Planning Guidance for response to a nuclear detonation of Us Department of Home land security (DHS), the entire affected area was grouped into three zones such as Light Damage Zone (LDZ), Moderate Damage Zones (MDZ) and Severe Damage Zones (SDZ). The inner zone (SDZ) was considered as completely devastated or collapsed zone; hence this zone is also called as No Go Zone (NGZ). The table (Table 7) shows the damage zones for the blast affected region.

Table 6: Relation of peak overpressure and distance for a $15 \mathrm{KT}$ explosion (Comparison with National Atmospheric Release Advisory Centre (NARAC) data)

\begin{tabular}{llll}
\hline & \multicolumn{2}{l}{ Distance from Ground Zero $[\mathrm{km}]$} \\
$\begin{array}{l}\text { Overpressure } \\
(\mathrm{psi})\end{array}$ & $\begin{array}{l}\text { Newmark and } \\
\text { Hansen }\end{array}$ & NARAC & $\begin{array}{l}\text { Area of affected } \\
\text { Zones }\left(\mathrm{Km}^{2}\right)\end{array}$ \\
\hline 75 & 0.32 & 0.30 & 0.0710 \\
50 & 0.38 & 0.36 & 0.0310 \\
30 & 0.47 & 0.45 & 0.0570 \\
20 & 0.57 & 0.54 & 0.0700 \\
15 & 0.66 & 0.62 & 0.0730 \\
8 & 0.91 & 0.85 & 0.2650 \\
5 & 1.18 & 1.10 & 0.3860 \\
0.5 & 4.86 & 4.68 & 16.252 \\
\hline
\end{tabular}

Table 7: Damage Zones in Blast affected region

\begin{tabular}{llll}
\hline Blast affected zones & $\begin{array}{l}\text { Peak over } \\
\text { Pressure (Psi) }\end{array}$ & $\begin{array}{l}\text { Distance } \\
(\mathrm{Km})\end{array}$ & $\begin{array}{l}\text { Area } \\
\left(\mathrm{Km}^{2}\right)\end{array}$ \\
\hline Light Damage Zone (LDZ) & $0.5-5$ & $1.18-4.86$ & 16.252 \\
Moderate Damage Zone (MDZ) & $5-15$ & $0.66-1.18$ & 0.6483 \\
& $15-20$ & & \\
Severe Damage Zone (SDZ) & $20-30$ & Ground Zero-0.66 & \\
(No-go Zone) & $30-50$ & & 0.302 \\
& $50-75$ & & \\
& $>75$ & & \\
\hline
\end{tabular}




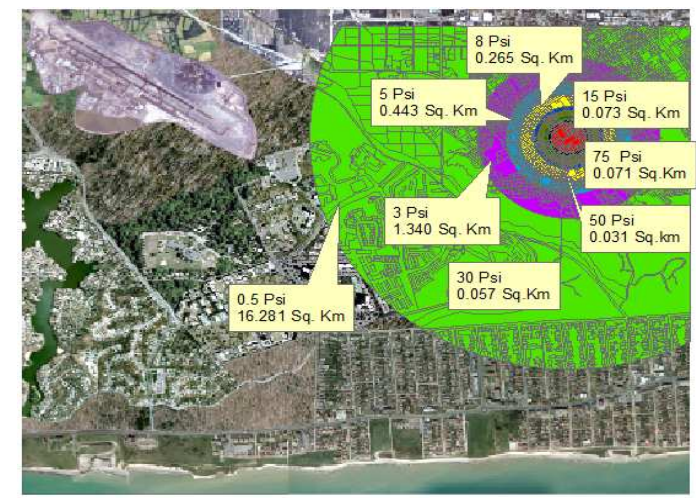

Fig. 7: GIS generated raster model for blast affected zone of the study area (15 kt yield detonation)

The blast effects on the buildings were modeled using the powerful Geographical Information System tool ARC GIS. Buffer zones were created in digitized vector data according to the radius arrived from the above tabular column. The radiuses were calculated from ground zero and buffer zones were created for the three zones.

\section{RESULTS AND DISCUSSION}

The raster data of the model city was digitized and to the spatial data attribute data was added. A total of 9560 polygons were developed for the model city. In the model city the residential area was selected for the detonation of hypothetical nuclear explosion and the effects were shown in the figure given below (Fig. 8). In the output the outer most zone given in green colour was considered as the Light damage zone, whereas yellow colour shows the Moderate damage zone and the inner most indicated in red colour is the Severe damage zone or No Go Zone (NGZ). A complete damage assessment was made on the study area and the results were tabulated below. The graphical representation shows the clear view of damages on structures and population in the study area.

Blast effects in light damage zone: In this zone the maximum blast overpressure was 5 psi and minimum 0.5 psi.

As per the literature there may be some major damages on masonry buildings and wooden structures but the RCC structures may withstand the pressure except few minor damages. As far as glass is concerned at $0.5 \mathrm{psi}$ there may be shattering of glass pieces in almost all buildings. The population living in this zone may face Threshold for eardrum rupture. The table below (Table 8) shows clearly the number of buildings present in this zone and number of buildings affected partially and fully. The total population living in this zone is also listed below in the table.

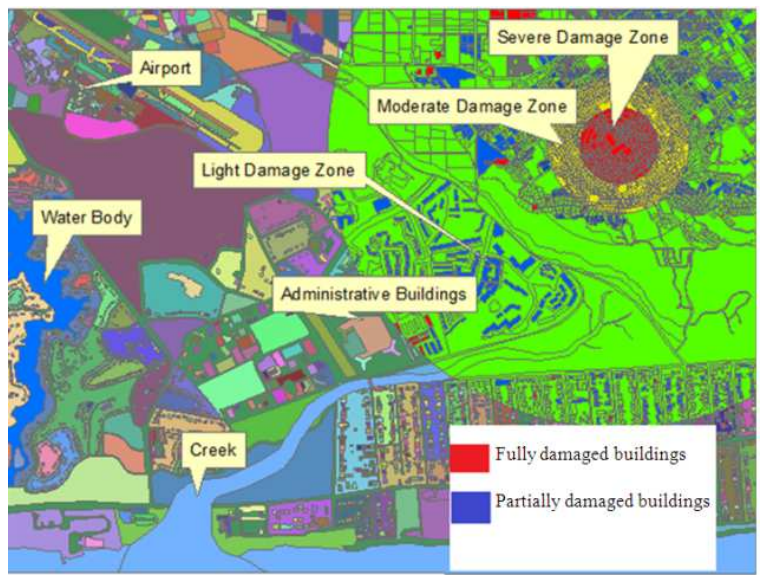

Fig. 8: ARC GIS generated vector model showing damage zones

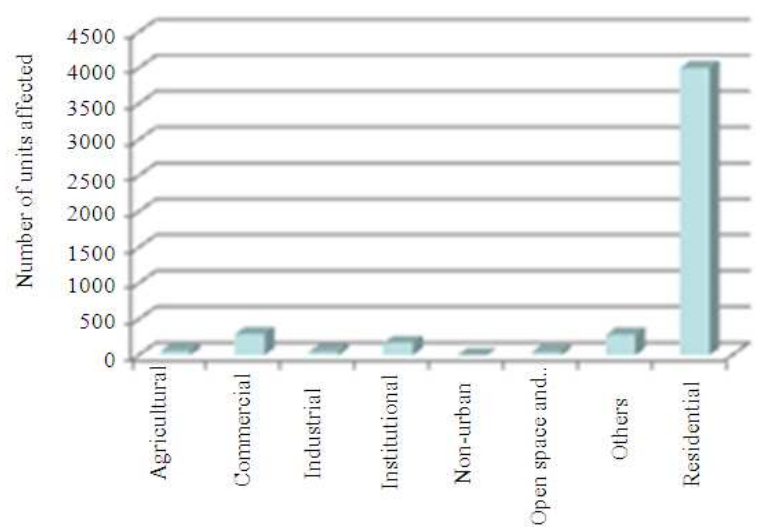

(a)

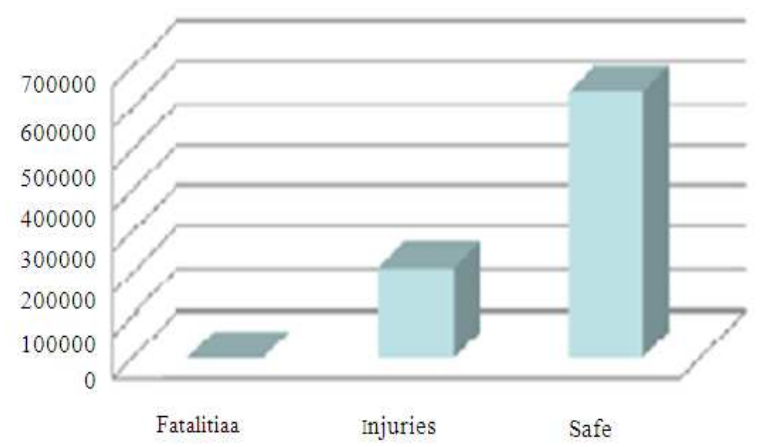

(b)

Fig. 9: (a) Number of units in LDZ (b) affected population in LDZ

The bar charts shown in figure (Fig. 9a and b) specify the total number of structural units (land use) and the affected population in this zone. Blast casualties may occur due to the direct action of the pressure wave, 
impact of missiles and fragments and whole body translation and impact. The destructiveness of the blast is a function of its peak overpressure and duration of the positive pressure wave against the exposed population.

Blast effects in moderate damage zone: In this zone the maximum blast overpressure was $15 \mathrm{psi}$ and minimum 5 psi. As per the literature there may be some major damages to RCC buildings and the masonry and wooden structures will be collapsed completely. The Engineered structures which were constructed with proper Earthquake design to withstand lateral loadings may be considered as safe structures and however there may be shattering of glass in all the buildings.

The population living in this zone may face Threshold for serious lung damage. The table (Table 9) shows clearly the number of buildings present in this zone and number of buildings affected partially and fully. The total population living in this zone is also listed below in the table.

The bar charts shown in figure below (Fig. 10a and b) specify the total number of structural units (land use) and the affected population in moderate damage zone. Blast casualties when compared to the light damage zone were elevated. Several people living in this zone may also severely affect by nuclear radiation with respect to the wind speed.

Blast effects in severe damage zone: In this zone the maximum blast overpressure was 75-100 psi and minimum 15 psi. This zone was considered as highly dangerous zone hence it is also called as no-go zone. The structures present in this zone will devastate completely. Even engineered structures designed to a maximum withstanding capacity or blast resistant structures will collapse within a short duration of time. There will not be any time limit for the people to escape or survive. In this zone $50 \%$ of the population may face incidence of fatal lung damage and remaining population may be killed due to the collapse of the buildings and buried inside the debris. The table (Table 10) shows clearly the number of buildings present in this zone and number of buildings affected partially and fully. The total population living in this zone is also listed below in the table.

The bar charts shown in figure below (Fig. $11 \mathrm{a}$ and b) indicates the total number of structural units (land use) damaged and the affected population in severe damage zone. Blast casualties when compared to the light damage zone and moderate zone will be very higher. Almost the people living in this zone mace face fatal deaths.

Table 8: Details of affected structures and affected population in light damage zone

\begin{tabular}{llll}
\hline Land use & $\begin{array}{l}\text { Affected } \\
\text { units }\end{array}$ & Population & \multicolumn{1}{l}{$\begin{array}{l}\text { Fully affected } \\
\text { buildings }\end{array}$} \\
\hline Agricultural & 6100 & 00000 & 0000 \\
Commercial & 2950 & 87256 & 2400 \\
Industrial & 5200 & 22111 & 1200 \\
Institutional & 1680 & 63530 & 8000 \\
Non-Urban & 3000 & 00000 & 0000 \\
Open Space and Recreation & 4700 & 15820 & 0000 \\
Others & 2870 & 00000 & 0000 \\
Residential & 4001 & 676632 & 1604 \\
Grand Total & 4914 & 851111 & 160 \\
\hline
\end{tabular}

Table 9: Details of affected structures and affected population in moderate damage zone

\begin{tabular}{|c|c|c|c|c|}
\hline Land use & Affected units & Population & $\begin{array}{l}\text { Partially affected } \\
\text { buildings }\end{array}$ & $\begin{array}{l}\text { Fully affected } \\
\text { buildings }\end{array}$ \\
\hline Commercial & 570 & 959000 & 380 & 290 \\
\hline Institutional & 320 & 109620 & 140 & 180 \\
\hline Open space and recreation & 700 & 694400 & 300 & 400 \\
\hline Others & 170 & 000000 & 000 & 170 \\
\hline Residential & 767 & 997390 & 447 & 116 \\
\hline Grand total & 880 & 127235 & 502 & 184 \\
\hline
\end{tabular}

Table 10: Details of affected structures and affected population in moderate damage zone

\begin{tabular}{|c|c|c|c|c|}
\hline Land use & Affected units & Population & $\begin{array}{l}\text { Partially affected } \\
\text { buildings }\end{array}$ & $\begin{array}{l}\text { Fully affected } \\
\text { buildings }\end{array}$ \\
\hline Commercial & 9800 & 217700 & - & 9800 \\
\hline Institutional & 8500 & 188580 & - & 8500 \\
\hline Open space and recreation & 3000 & 173600 & - & 3000 \\
\hline Others & 1200 & 000000 & - & 1200 \\
\hline Residential & 1249 & 188348 & - & 124 \\
\hline Grand total & 1447 & 230712 & - & $144^{7}$ \\
\hline
\end{tabular}


J. Computer Sci., 8 (9): 1520-1530, 2012

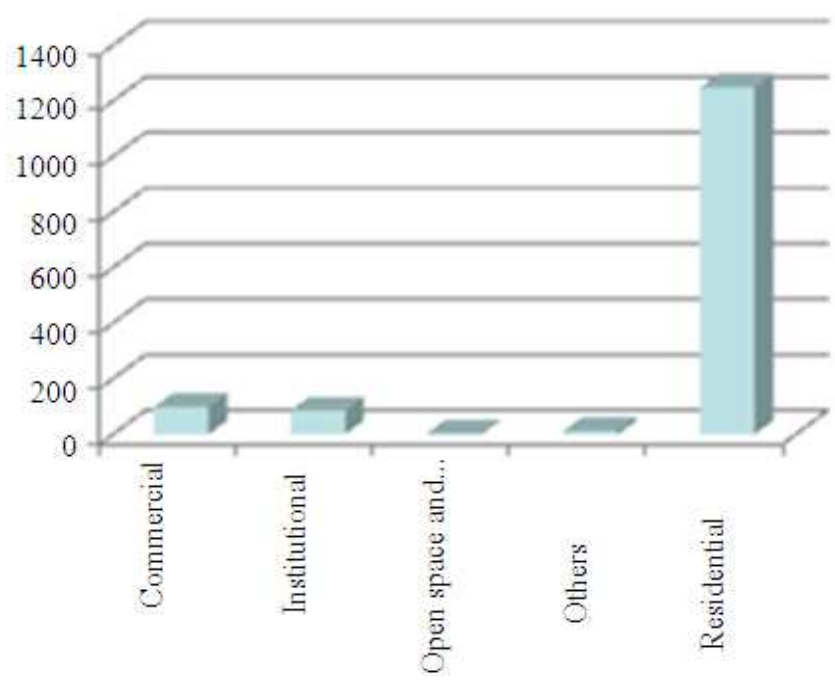

Number of units affected

(a)

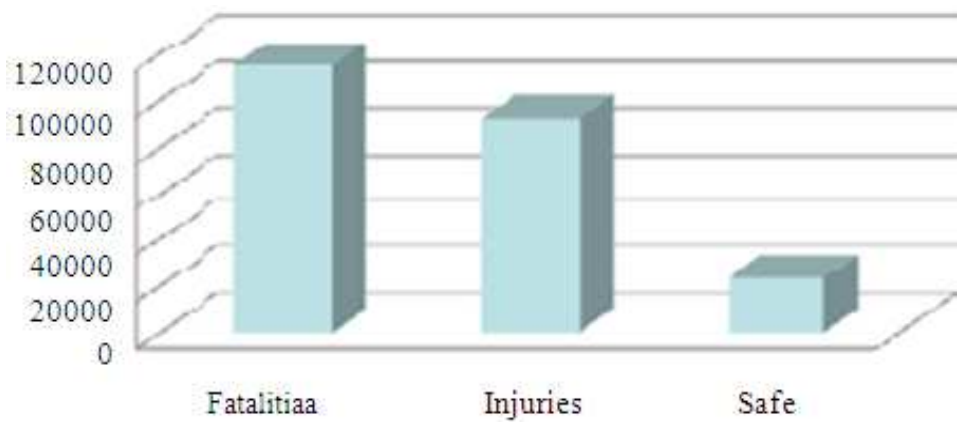

(b)

Fig. 10: (a) Number of units in MDZ (b) affected population in MDZ

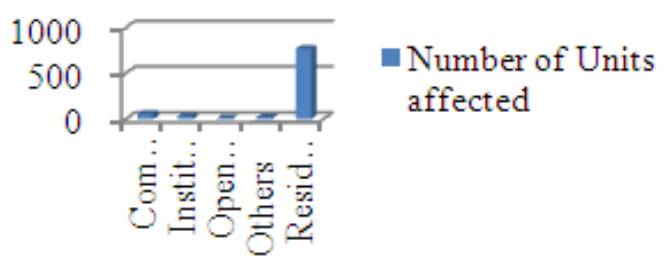

(a)

200000

100000

0

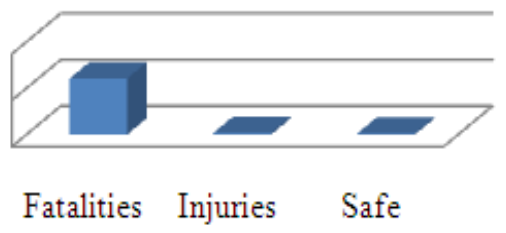

(b)

Fig. 11: (a) Number of units in SDZ population in SDZ

\section{CONCLUSION}

The above description was set in the context of a model Indian city. As proliferation of nuclear weapons continues, there is a greater risk that a tropical city may be attacked. In such circumstances, the buildings and other infrastructures may be affected partially or fully along with existing population, because many of the dwellings would be of light construction and a higher proportion of the population would be likely to be in the open at the time of the explosion. From the above study it is observed that Shock waves and accompanying highspeed winds could crush people or throw them around. In the model city the major structural damages occurred in residential buildings. Almost the numbers of partially and fully affected buildings were residential buildings. This may lead to severe damages to the existing population.

Based on the assumed population data, the historical experiences of Hiroshima and Nagasaki and different physical models, we have estimated short-term 
casualties and structural damages from a hypothetical explosion over model City. For a 15 kiloton explosion, the number of deaths due to blast effects alone would range between 100,000-300,000. This figure may increase because of the dangerous radiation fall outs. Totally around 5000-6000 structures in the hypothetical city are damaged due to the $15 \mathrm{Kt}$ nuclear explosion. From this study we are recommending the city planners to consider this major issue and to find remedies while designing the future cities.

\section{REFERENCES}

Bangash, M.Y.H., 1993. Impact and Explosion: Analysis and Design. 1st Edn., CRC Press, Boca Raton, ISBN10: 0849377420 , pp: 856.

Brode, H.L., 1955. Numerical solutions of spherical blast waves. J. Applied Phys., 26: 766-766. DOI: 10.1063/1.1722085

DCR, 2004. Development control rules for chennai metropolitan area. Chennai Metropolitan Development Authority.

FEMA, 2010. Planning Guidance for Response to a Nuclear Detonation. 2nd Edn., National Security Staff.

Glasstone S. and P.J. Dolan, 1977. The Effects of nuclear weapons. U.S. Government Publication.

Hiroshima, N., 1981. The Physical, Medical, and Social Effects of the Atomic Bombings. 1st Edn., Basic Books, New York, pp: 706.

Kinney, G.F. and K.J. Graham, 1985. Explosive Shocks in Air. 2nd Edn., Springer, Verlag, ISBN-10: 0387151478, pp: 269.
Mays, G. and P. Smith,1995. Blast Effects on Buildings. 2nd Edn., American Society of Civil Engineers, London, ISBN-10: 0727720309, pp: 121.

Mendis, P.A. and T. Ngo, 2002. Assessment of tall buildings under blast loading and aircraft impact, toward a better built environment, innovation, sustainability and information technolology. Int. Assoc. Bridge Stru. Eng. Aus.

Mills, H.D., M. Dyer and R.C. Linger, 1987. Cleanroom software engineering. University of Tennessee.

Newmark, N.M., 1961. Protective Construction Review Guide-hardening. 1st Edn., Defense Technical Information Center, pp: 324.

Ngo, T.P., A. Mendis and J.R. Gupta, 2007. Blast loading and blast effects on structures-an overview. EJSE Special Issue Loading on Structures.

Phillips, A.F., 2003. The effects of a nuclear bomb explosion on the inhabitants of a city.

Ramana, M.V., 1998. Effects of a nuclear weapon on bombay. Medicine and Global Survival.

Remennikov, A.M., 2003. A review of methods for predicting bomb blast effects on buildings. J. Battlefield Technol., 6: 5-10.

Richard, L. and A. Garwinm, 2010. Nuclear explosion in a city or an attack on a nuclear reactor. Bridge Nat. Acad. Eng.

TM 5-1300, 1990. The design of structures to resist the effects of accidental explosions. Technical Manual, US Department of the Army, Navy and Air Force. Washington DC. 